proximal carpal bones and the proximal carpal canal in female patients and controls $(r=0.48$, $\mathrm{n}=31, \mathrm{p}<0.01 ; \mathrm{r}=0.66, \mathrm{n}=31, \mathrm{p}<0.001)$; no such correlation was found in the male control groups $(r=0.05, n=30, p>0.05)$. This suggests a totally different anatomical relation between carpal canal and bones in the male group and again may explain the female propensity for this condition.

Finally, I should point out that the examination was done with standard postures (using a plastic splint) and the method was found to be accurate within $1_{0}^{\circ}$ in repeated measurements.

\section{$S$ DEKEL}

Nuffield Department of Orthopaedic Surgery, Nuffield Orthopaedic Centre,
Oxford OX3 7LD

\section{Brachial plexus injuries in motorcyclists}

SIR,-May I comment on your interesting leading article on brachial plexus injury in motorcyclist (24 May, p 1242)? The only point that I would take issue over is the statement that with a severe injury causing preganglionic avulsion of all roots the best long-term result will come from amputation, arthrodesis, and a prosthesis. This used to be the teaching here some 10 years ago, but recent follow-ups from this hospital ${ }^{1}$ have shown that few patients actually use their prosthesis.

Most patients with avulsion lesions lose their scapular-thoracic control and therefore are unable to use their prosthesis functionally. Very few use it cosmetically. Recently we have shown that the flail arm splint ${ }^{2}$ allows the patient to retain his arm and yet provides a variety of functions both for work and for hobbies. We therefore feel that amputation is no longer the treatment of choice and that the flail arm splint should always be tried and amputation advised only if there are clear indications such as trophic changes and infected ulcers, which are remarkably rare, or if there is a quite clear indication in the patient's job that he will be able to do it better with an artificial limb than with a splint.

C B WYNN PARRY

PNI Unit and Hand Clinic,

Royal National Orthopaedic Hospital,

London W1N 6AD

1 Ransford A, Hughes SP. $f$ Bone ft Surg 1977;59B:

2 Wynn Parry CB. Injury 1979;11:265-85.

\section{Hypothyroidism in Down's syndrome}

SIR,-It was gratifying to read of the study of thyroid function by $\mathrm{Dr} \mathrm{E}$ de $\mathrm{H}$ Lobo and others (24 May, p 1253), which confirmed the finding of my colleagues and myself ${ }^{1}$ of a high incidence of gross hypothyroidism in subjects with Down's syndrome. The omission of any reference to our study of 84 adults with Down's syndrome is presumably an oversight as this has been widely reported, and was confirmed by American ${ }^{2}$ and Scandinavian ${ }^{3}$ studies.

The original paper made two points about this phenomenon which obviously require to be restated. Firstly, the mean serum thyroxine levels in Down's syndrome are significantly lower than in controls, presumably because of the low thyroid mass in these individuals and certainly not owing to hypopituitarism. ${ }^{4}$ Secondly, gross hypothyroidism seems to be particularly common in those individuals with thyroid antibodies-indeed in our study all those with such antibodies displayed evidence of biochemical hypothyroidism and deterioration of thyroid function over a two-year period. ${ }^{5}$

The study of Dr Lobo and his colleagues appears to confirm these findings as all the cases with gross hypothyroidism were positive for thyroid antibody. I would dispute their assertion that "the likelihood of abnormal thyroid function increased with age" since their own figures do nothing to prove this; and the study which they quote, by Baxter et $a l,{ }^{6}$ was not a study as such but a case report of 11 hypothyroid aged subjects with Down's syndrome. Out studies showed that the phenomenon was not age related.

It is important that the difficulty of clinical diagnosis should be emphasised, a point which has been made by me in almost identical terms to those used by $\mathrm{Dr}$ Lobo and his colleagues. ${ }^{7}$ It now ought to be established practice that all patients with Down's syndrome have biochemical tests of thyroid function carried out regularly, and that those with thyroid antibodies should be considered at particular risk of developing hypothyroidism.

\section{University Department of General Practice,}

1 Murdoch JC, Ratcliffe WA, McLarty DG, Rodger JC, Ratcliffe JG. $\mathcal{F}$ Clin Endocrinol Metab 1977;44:453. Sare Z, Ruvalcaba RHA, Kelley VC. Clin Genetics 1978;14:154-8.

${ }^{3}$ Korsager S, Chatham EM, Østergaard Kristensen HP. Acta Endocrinol 1978;88:48-54.

Murdoch JC, Gray CA, McLarty DA, Ratcliffe JG. F Ment Defic-Res 1979;22:273.

early mortality of adulsible factors involved in the early mortality of adults with Down's syndrom

' Baxter RG, Larkins RC, Martin FIR, Hayma P Myles K, Ryan L. Lancet 1975;ii:794-6.

${ }^{7}$ Murdoch JC. Update 1978;17:1374-9.

\section{Education, screening, and genetic}

counselling in thalassaemia

SIR,-In the paper by Dr B Modell and others (7 June, p 1347) we read that nearly all Cypriot couples said that people should know before they got married the risks of the thalassaemias, in order to make their decisions about marriage and reproduction responsibly. Among the various possible strategies of health education and genetic counselling, they quote a proposal that the screening could be performed and information given to 13year-old students of secondary schools.

Our centre has been carrying out yearly since October of 1975 this kind of screening on the whole scholastic population attending the third class of the secondary schools (1314-year-old students) of the Latium region (the region whose capital is Rome). So far five screening campaigns have been carried out, and 4630 heterozygotes for thalassaemia were identified and adequately informed out of a total of 192147 students tested. People received this initiative well and high percentages participated.

This work has been sponsored by the regional health department (Assessorato alla Sanità) as one of its public health services. I has promoted in the course of five years a large increase in the general knowledge about thalassaemias not only among the student but also by and large in the population, and this in turn has resulted in a tremendous expansion of the number of spontaneous requests for the relevant tests by engaged and married couples and by pregnant women. These results show that it is a social and medical duty to offer information and screening to young people before marriage and procreation, and not just after these events. A small percentage of couples at risk reject prenatal diagnosis or selective abortion: this has been found not only in Great Britain but in Italy as well. It seems likely that a larger percentage of young thalassaemic people-becoming aware before getting married of the risks of their genotype-will opt for a non-thalassaemic partner.

We commend to every country with thalassaemia, as well as to the other Italian regions, the screening strategy we have developed in Latium, which is described in detail in a paper to be published by the fournal of Medical Genetics.

\section{E Silvestroni}

I BIANCO

Centro di Studi della Microcitemia di Roma,

00161 Rome, Italy

\section{Clinical use of nicotine chewing-gum}

SIR,-The paper by Dr M A H Russell and others (28 June, p 1599) was indeed welcome, if only for enlarging on the scanty prescribing information presented by the advertisement. None the less, many questions remain unanswered, as the authors of the paper would agree.

What is most surprising to me is the fact that this substance needs to be advertised in the medical press at all. Smokers currently walk into tobacconists to purchase an average of $1 \mathrm{mg}$ of nicotine per cigarette in quantities as large as they care to choose, but are now going to have to receive a private prescription from a doctor to receive 2 or $4 \mathrm{mg}$ of nicotine per unit in a fashion that will continue to be controlled by prescription. Where is the logic?

Can we really be sure that cigarette dependence will not be replaced by gum dependence? If this happens, is the burden of prescribing going to fall on doctors ad infinitum, as it has unfortunately done by the careless repeat prescribing of anxiolytic drugs over the last decade or so?

Alcohol is a dangerous drug, but is at present freely available without prescription. Does the introduction of this present substance (or at least its availability through prescription only) make any more sense than the attempt to wean alcoholics away from alcohol by prescriptions for Mandrax, amphetamines, or the like?

London SW7 2NG

JOHN WEST

\section{Delay in publishing ABPI Code of Practice Committee rulings}

SIR,-I am surprised to hear that the Code of Practice Committee of the Association of the British Pharmaceutical Industry does not necessarily release its rulings immediately. The Constitution and Procedure for the Code of Practice Committee states, "the committee shall submit a report of its work to the board each year and the board will authorise the publication, within and outside the Association, of information contained in or based upon such a report." Because of this built-in delay of up to one year it seems likely that by the 